\title{
Statistical Evaluation of the Corrosive Wear of Fuel Injector Elements Used in Common Rail Systems
}

\author{
Karol Franciszek Abramek - Tomasz Stoeck* - Tomasz Osipowicz \\ The West Pomeranian University of Technology, The Department of Automotive Engineering, Poland
}

This paper presents the causes and consequences of corrosion that has a destructive impact on the technical condition and operational reliability of Common Rail fuel injectors. The analysis included selected components indicating the elements and assemblies most frequently subject to destructive processes. Statistical evaluation of the corrosive wear of fuel injector elements was carried out based on experimental data obtained when verifying the fuel injector designs of different generations using the concept of corrosion density, related to our own classification of the degree of wear. The repair efficiency percentages were specified, taking into account specific operational mileages. Typical problems with the fuel injectors of leading manufacturers, with examples, are also shown.

Keywords: common rail fuel injectors, component corrosion, statistical evaluation

Highlights

- Nozzle bodies and control valve assemblies proved to be most prone to corrosion.

- The wear of electrical elements is least frequent.

- An increase in the injection pressure leads to intensification of corrosive wear.

- Repair is no longer effective with high operational mileages.

- $\quad$ Availability of spare parts has a fundamental impact on fuel injector repair.

\section{INTRODUCTION}

The process of wear can be defined as changes in the injection system as a result of use and leading to a gradual loss of functionality or permanent damage. Due to exceptionally difficult operating conditions, the elements of common rail systems being most prone to defects are fuel injectors [1]. Among other things, corrosion due to chemical or electrochemical mechanisms plays an important role in causing defects in fuel injection elements. Firstly, corrosion may affect sub-assemblies that have direct contact with the fuel and is found in the surface layers of friction pairs having different properties than the original material. Secondly, galvanic cells are formed which lead to reduction and oxidation reactions in the presence of electrolytes [2]. Accelerated wear may be defined as a situation in which the intensity of the formation of corrosion products (e.g. oxides, hydroxides) is higher than the surface destruction as a result of boundary friction.

The corrosive effects of diesel oil depends largely on acidic oxygen complexes of natural origin or on the ageing processes being taking place in the oil itself, as well as on the content of sulphur and water compounds. Thus, the quality and type of fuel that feeds an engine substantially affects the intensity of the processes being discussed. Recently, fatty acid methyl esters (FAME) have been popularised as biodiesels, mainly for ecological reasons. Many researchers have shown, however, that fuels of this group are characterised by a high degree of oxidation [3], as well as a tendency to polymerisation [4] and deposit formation [5], and increased microbial degradation [6]. High hygroscopicity of FAMEs, affecting water absorption from the surroundings and increasing corrosion aggressiveness, is also very important. In some papers [7] and [8], it has been pointed out that corrosive action on metals is increased by the presence of alcohol, glycerol and free fatty acids. However, not all of these compounds are post-production residues of esterification. For example, it has been shown that dehydrated ethanol, applied in mixtures with FAME or diesel oil to improve starting properties, may have a corroding effect on the fuel pump and injector elements and, additionally, induce seal swelling and stiffening [9] and [10].

A separate issue is light heating oils, which are used illegally to fuel engines of commercial vehicles and to which red dye is added in order to identify the use of such oil. According to Kowalski [11], the properties of light heating oils do not fundamentally depart from those of diesel oils and their use should not cause major problems from the operational point of view. However, it is noteworthy that procedures for dye removal require the application of sulphuric acid, which has an exceptionally aggressive effect on metals. Attempts to neutralise this acid lead to the development of small grains initiating accelerated abrasive wear on the injection system. It has been

*Corr. Author's Address: The West Pomeranian University of Technology, The Department of Automotive Engineering, Piastów 19 Ave., 
emphasised in another paper [12] that one of the elementary mistakes being made by the users of agricultural vehicles is the use of such heating oil, which leads to damages in the respective assemblies of force pumps and defects in fuel injector sprayers.

Besides the quality and type of fuel, other factors having a significant impact on the intensity of corrosion occurrence are also noted in the reference literature. They include, among others, high temperature and pressure occurring in the combustion chamber [13], direct contact with fuel [14], ballistic phenomena [15], and turbulent fluid flow [16]. Researchers have also brought up the problems of accompanying processes, i.e. erosion [17] and cavitation [18]. Hence, a precision pair (needle and nozzle) affected by the phenomena mentioned above were examined. There are no data referring to other fuel injector elements and assemblies fulfilling executive and control functions. Our studies have shown that corrosion affects the parts of valve and armature assemblies almost equally.

\section{EXPERIMENTAL METHODS}

The primary objective of this study was to statistically evaluate the corrosive wear of fuel injector elements of different types and manufacturers, taking into account the factors that have a negative effect on their operational reliability. In the analysis, the utilitarian nature of the repairs being conducted was also considered, and thus the possibility of eliminating the deficiencies being discussed, with a view to the degree of wear of respective parts and the possibility of their replacement.

\subsection{Test Object}

The test object was common rail fuel injectors. A total of 3200 from a number leading manufacturers of fuel injection equipment such as Bosch, Delphi, Denso and Siemens were tested. Examination and verification of respective fuel injector components were conducted at the laboratories of VASCO Co. Ltd in Mierzyn, which co-operates with the Department of Automotive Engineering of the West Pomeranian University of Technology in Szczecin. The following equipment, among others, was used in this process: test benches (EPS 200 Bosch, Diesel Bench CRU 2 Zapp, Diesel Tech DS2 Zapp), a microscope with a camera to record digital images (FL150/70), ultrasonic cleaners (Elma Elmasonic S $10 \mathrm{H}$, Carbon Tech Ultrasonic Bath S15/C2), vices and fuel injector disassembly and assembly kits and a torque wrench set.
Table 1. Graphical classification of corrosion and the criteria of adopted classification illustrated by examples (nozzle and valve seat)

\begin{tabular}{ll}
\hline Level & 0 \\
\hline Evaluation & No corrosion \\
\hline Classification criteria & No corrosion traces found \\
\hline & \\
& \\
\hline Examples & 1 \\
\hline Level & Low corrosion \\
\hline Evaluation & Corrosion covered up to 19\% of the area of \\
\hline
\end{tabular}
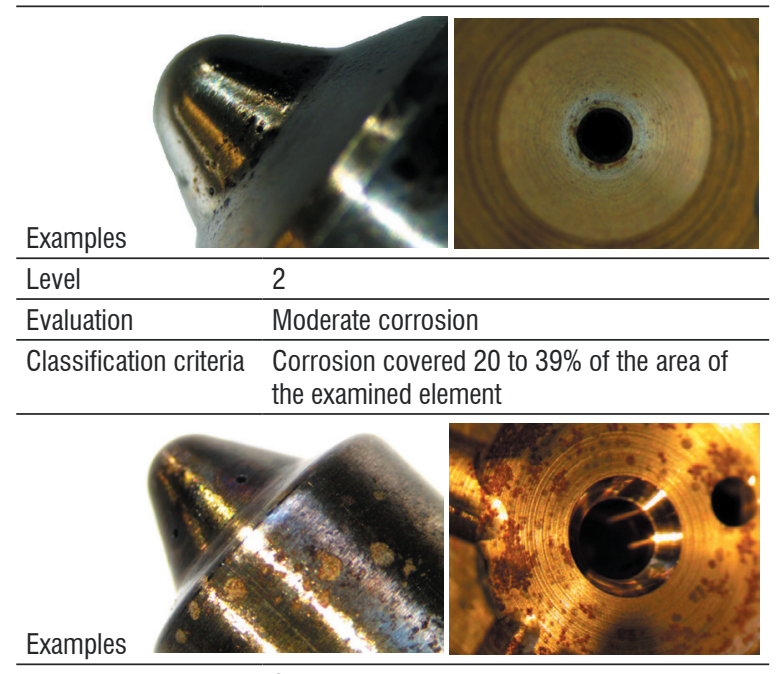

\begin{tabular}{ll}
\hline Level & 3 \\
\hline Evaluation & High corrosion \\
\hline Classification criteria & $\begin{array}{l}\text { Corrosion covered over 40\% of the area of } \\
\text { the examined element (or was more localized } \\
\text { nature but of high intensity) }\end{array}$ \\
\hline
\end{tabular}

\subsection{Scope and Criteria of Evaluation}

An experimental study was conducted according to our own methods, which included three implementation stages. In the first stage, fuel injectors were disassembled into components that were subject to detailed visual inspection and verification. Evaluation of the corrosion level was performed using visual methods as well as under a high magnification 
laboratory microscope. The next stage was initiated by cleaning in ultrasonic baths, excluding components sensitive to the effect of cleaning fluid, e.g. solenoid valves and injector bodies with embedded piezoelectric crystal stacks. The parts being qualified for replacement were also left out. After thorough drying and blowing off with compressed air, fuel injectors were assembled and then the test stage was conducted on test benches (last stage). Possible fuel delivery correction included only the designs for which unsatisfactory sampling results had been obtained.

In order to conduct statistical analysis, the following visual levels of corrosion evaluation were established: 0 no corrosion, 1 low corrosion, 2 moderate corrosion, and 3 high corrosion. Examples of the graphical representation of adopted corrosion classification and its criteria are presented in Table 1. These fuel injector elements, which were eliminated due to pitting corrosion, most often of a local nature but of high intensity, are an exception. Although the size of the area affected by the changes was small, it was classified as level 3 (Fig. 1).

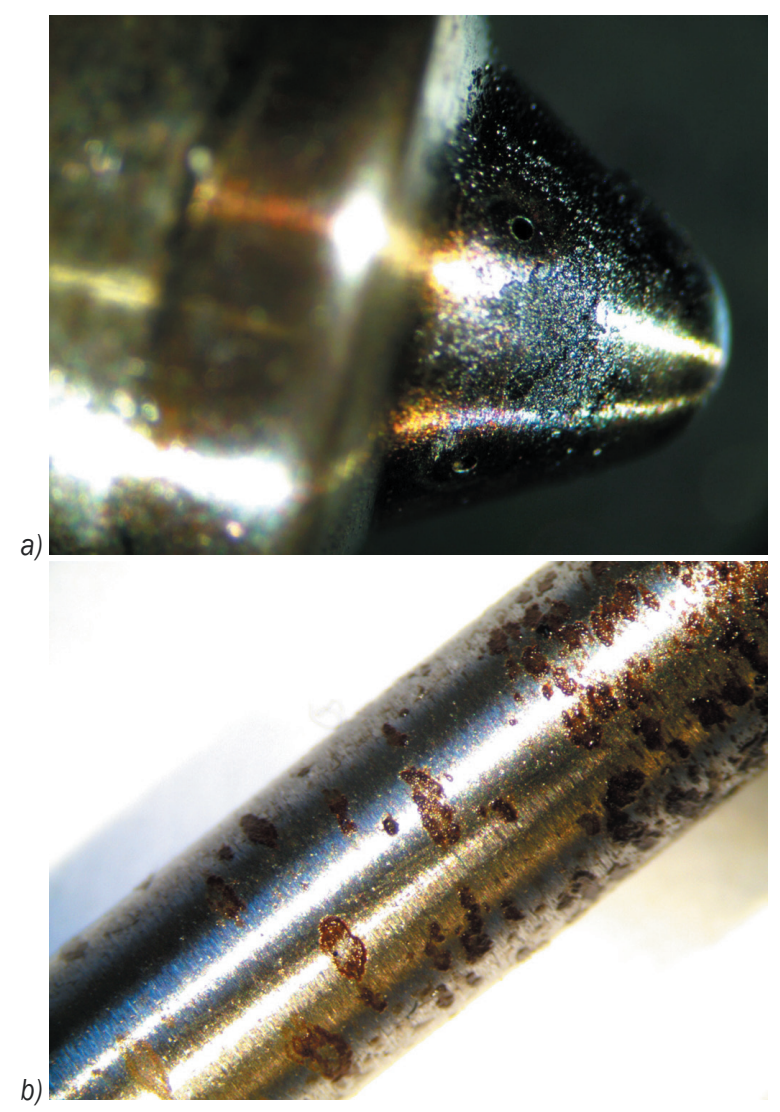

Fig. 1. Examples of pitting corrosion; a) Bosch fuel injector nozzle tip, and b) Denso needle
The results of the experiment were processed using the concept of corrosion density, the mathematical notation of which can be presented by the following equation [13]:

$$
D_{c}=\frac{\sum_{i=1}^{e} L_{i}}{e},
$$

where $D_{c}$ is corrosion density, $L_{i}$ level of corrosion classification for the $i^{\text {th }}$ element and $e$ is the number of elements.

For example, when examining Bosch fuel injectors, corrosion density was determined as an algebraic sum of the verified corrosion levels which referred to the total number of examined elements $e=2368$ :

$$
D_{c(\text { Bosch, neddes })}=\frac{(1+0+3+\ldots)}{2368} .
$$

\section{RESULTS AND DISCUSSION}

In Fig. 2 a histogram of the fuel injectors accepted for repair in VASCO over one year (11.2012-11.2013) is presented.

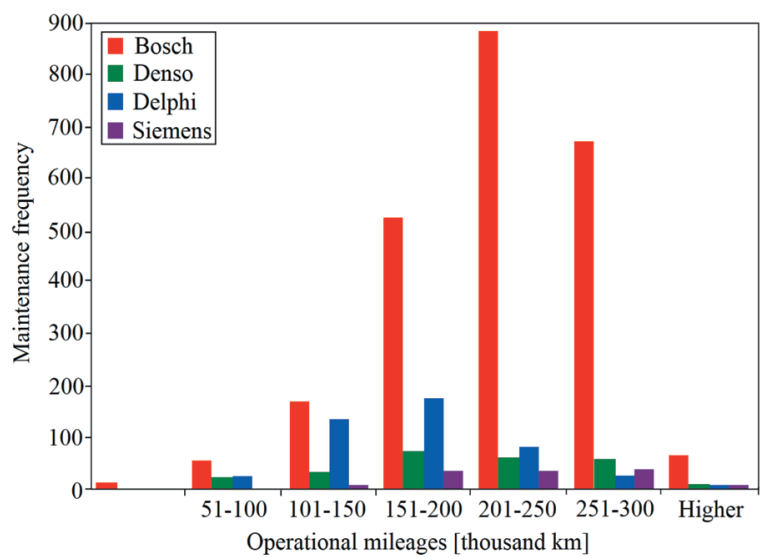

Fig. 2. Histogram of the fuel injectors accepted for repair in the test period

Fuel injectors by Bosch constituted nearly $75 \%$, which results from the dominance of this manufacturer in the segment of the automotive market under consideration. However, it is worth noting that $2 / 3$ of them were from vehicle engines with mileage over $201,000 \mathrm{~km}$. A similar correlation occurred only in Siemens products but these were solely piezoelectric fuel injectors, the maintenance of which was limited to cleaning and tests on test benches. Results for other fuel injector manufacturers constitute unimodal distributions, being characterised by moderate left- or 
right-sided asymmetry. In this respect, fuel injectors of the Delphi design performed least favourably, showing increased failure frequency after mileage of $101,000 \mathrm{~km}$. On the other hand, few problems are observed in the first and the last sections of the diagram. This is due to the fact that new vehicles are covered by the manufacturer's guarantee, while the questions of possible failures are usually examined at a service station. At the other end, few fuel injectors with high operational mileages were accepted because the efficiency of their repair was low.

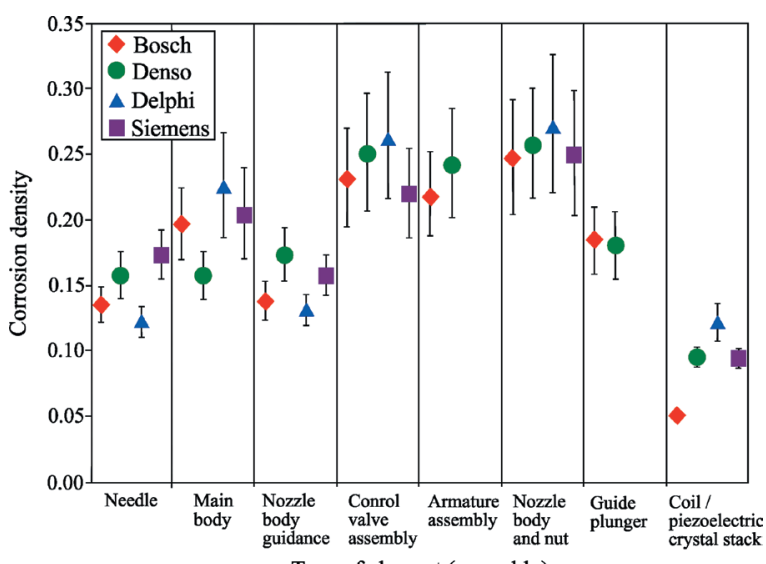

Type of element (assembly)

Fig. 3. Comparison of corrosion density for selected elements (assemblies) of the examined fuel injectors

Fuel injector nozzle bodies together with nuts and control valve assemblies proved to be the most prone to corrosion (Fig. 3). In the first case, a primary cause can be seen in the effect of high temperatures which induce accelerated degradation of the surface of metal, with an interaction of chemical and electrochemical reactions in the combustion chamber. However, it is worth noticing that corrosive processes affect the precision pair less, which has been confirmed by the results presented in paper [13]. For example, Delphi needles, being characterised by indents on the guide face made to preserve stable operation at higher pressures and under increased flow turbulence, performed most favourably in the given aspect. Corrosion mainly occurred in these depressions (Fig. $4 a)$, while its traces were observed only in 42 elements from among 448 examined ones. Causes for increased failure frequency at relatively low mileages may be explained by the wear of fuel pumps, particularly of the drive areas of force assemblies, which generates metal fillings that get inside the fuel injector. The sharp edges of the needle indents induce jamming of hard impurities and accelerated seizing of the precision pair. Accelerated destruction of the control assembly, which is also exposed to corrosion (first of all in the head seat and flange), erosion and cavitation processes, occurs similarly [17]. The solenoid coil, having frequent contact with fuel compared to that of other manufacturers, should also be mentioned. The seating of the element through almost the whole length of the body causes problems with O-ring seals, which may occur even with low operational mileages. Losses in material and corrosion were observed in the fuel injectors of the Ford Transit, Focus and Mondeo vehicle models.

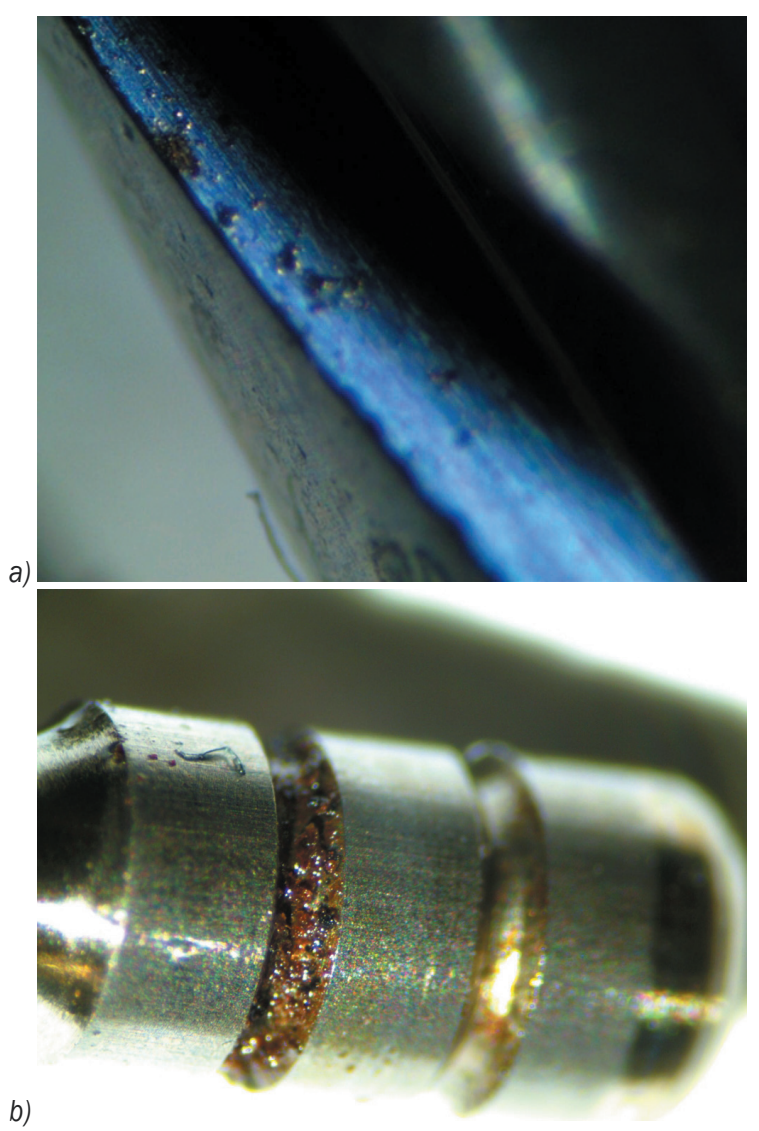

Fig. 4. Local corrosion of example parts of Delphi fuel injectors; a) needle and b) head

The verification being carried out showed that the wear of armature assembly found solely in the fuel injector designs of two manufacturers proceeds similarly to that of the valve arrangements. Changes are usually seen on the surface of the disc (much less often on that of the insert) and elements co-operating with it (Fig. 5). With a similar construction and principle of operation, a comparable value for the parameter under discussion was obtained, i.e.

$$
\begin{aligned}
& D_{c(\text { Bosch, armature assembly })}=0.22 \text { and } \\
& D_{c \text { (Denso, armature assembly })}=0.24 .
\end{aligned}
$$




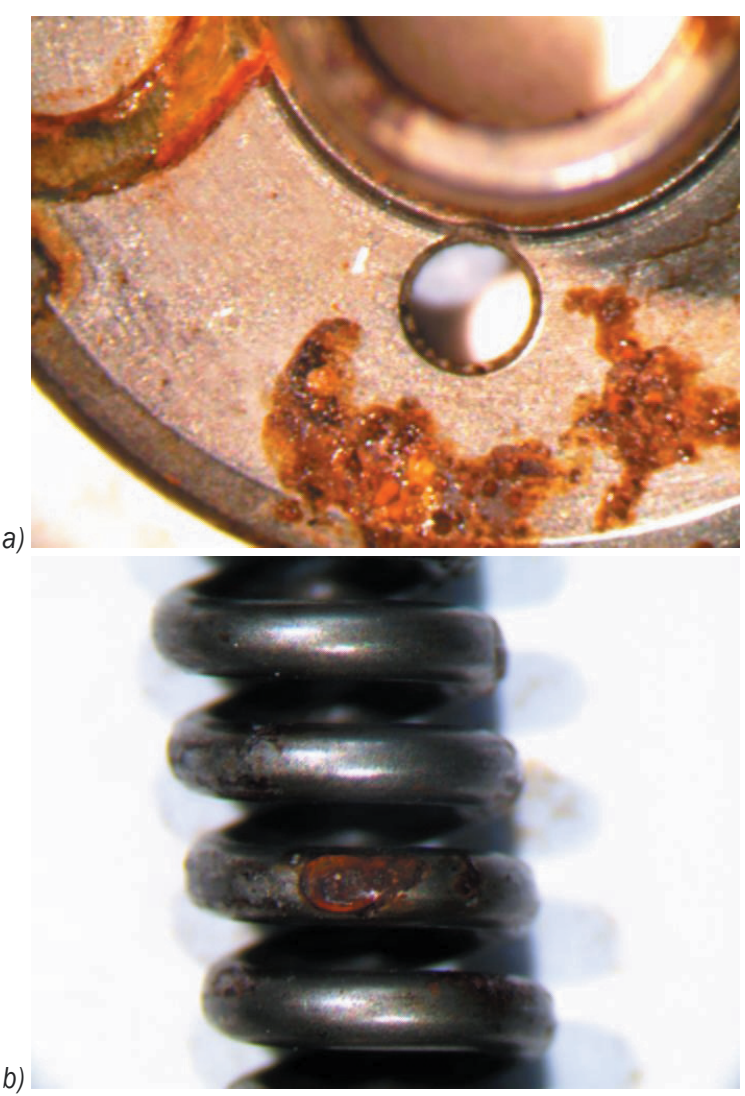

Fig. 5. Corrosion of Bosch fuel injector armature unit; a) disc plate and b) insert spring

From among all elements being affected by corrosion, nearly $58 \%$ were classified at level 1 . As a result, it was possible to remove corrosion traces after half-hour baths in ultrasonic cleaners. This is extremely important in the case of Denso products because availability of respective parts from this manufacturer, e.g. armature springs, locking rings and calibration washers, etc., is limited.

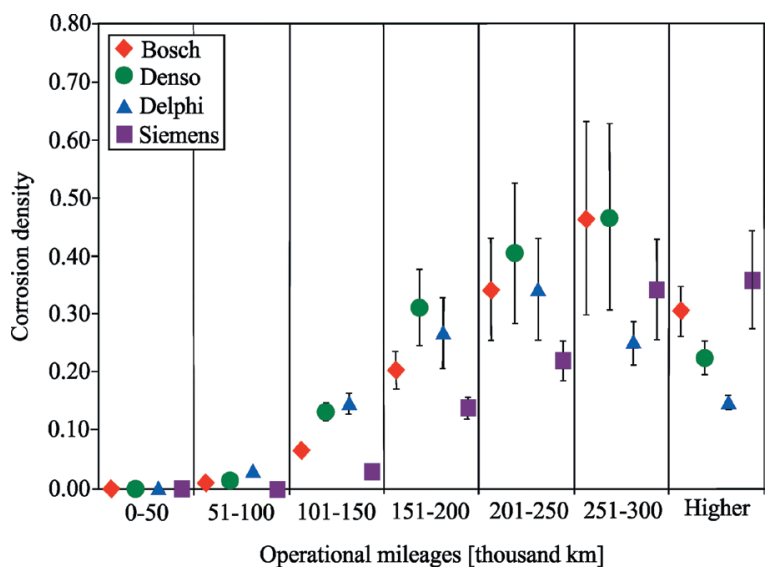

Fig. 6. Corrosion density according to operational mileages
Interesting results were obtained when comparing the corrosion density to operational mileages (Fig. 6). Over almost the whole range, the values of the corrosion density parameter show an upward tendency, which results from an increasing number of degraded elements being included at higher and higher levels of corrosion. A crucial change can be seen in the last interval. The trend here is disturbed due to a rapid decrease in the number of fuel injectors being accepted for repair because they are effectively irrepairable. Nevertheless, the corrosion density there is definitely higher than with mileages of 0 to 150 thousand $\mathrm{km}$. When analysing the presented data, one can conclude that the fuel injector designs using piezoelectric plate stacks by Siemens performed most favourably: wear traces on respective elements were observed less often and usually after a longer operation time. Unfortunately, both Siemans and Denso have a similar policy with respect to spare parts, i.e. there aren't any, which practically eliminates possibility of replacing these parts.

The statistics for the elements of Bosch fuel injectors looks completely different. Within the mileage range of 201 to 300 thousand $\mathrm{km}$, nearly $65 \%$ of all fuel injector designs of this manufacturer ware accepted for repair, obtaining as follows:

$$
\begin{aligned}
& D_{c(\text { Bosch, mileage: } 201 \text { to } 150)}=0.34 \text { and } \\
& D_{c(\text { Bosch, mileage: } 251 \text { to } 300)}=0.47 .
\end{aligned}
$$

These results are, at best, comparable with the others (except the Siemens products) but the market of available parts allows repairs over almost the full range, with the technology of this process being developed in detail and provided as needed. Relatively low values of corrosion density for the Delphi elements, particularly with moderate and high mileages, are also noteworthy. This means that increased failure frequency for these fuel injector designs depends largely on other factors. In this respect, improper co-operation of the control assembly (valve head and housing) and the precision pair (needle and nozzle) was the most frequently detected defect, resulting from accelerated abrasive wear of the co-operating surfaces.

In recent years, a tendency has been observed to increase the injection pressure, which has a significant effect on the improvement of engine operational indicators and the reduction of emission of toxic exhaust gas components. Deterioration of operating conditions forced an increase in strength requirements which are being accomplished by changes in the design and materials. Results of our own study show that, despite these measures, the parts of injectors operating at higher pressures are more 
prone to corrosive wear. Due to the sample size and availability of respective fuel injector generations, an analysis was conducted solely for products made by Bosch (Fig. 7). In successive intervals, a growing number of elements in the highest level of the adopted classification can be observed. A similar situation was obtained with corrosion density, except at a pressure area of $200 \mathrm{MPa}$, in which solenoid fuel injectors of the CRI 2.5 (Common Rail Injector) type had been only examined. Nevertheless, the number of 3rd level parts was three times larger when compared with the initial area where such generations as CRI 1.0, CRI 2.0 and additionally CRIN 1, i.e. the fuel injector designs being applied in engines of commercial vehicles (German: Nutzfahrzeug), were examined. A similar correlation is being found for the elements operating at a pressure of 160 to $180 \mathrm{MPa}$. The obtained results point to the necessity of a much broader use of materials, of which mainly fuel injector nozzles have been made so far, i.e. stellite, carbide-steel cermets. These are characterised by large dimensional stability at high temperatures but also by abrasion and corrosion resistance and resistance to the ataggressive effect of fuels [19].

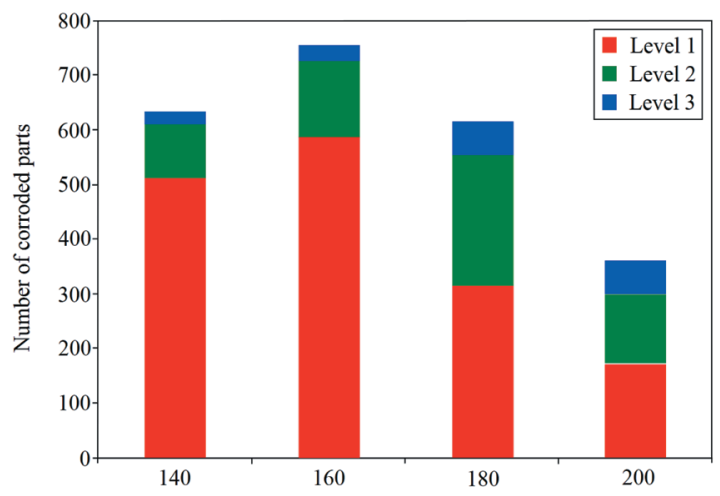

a)

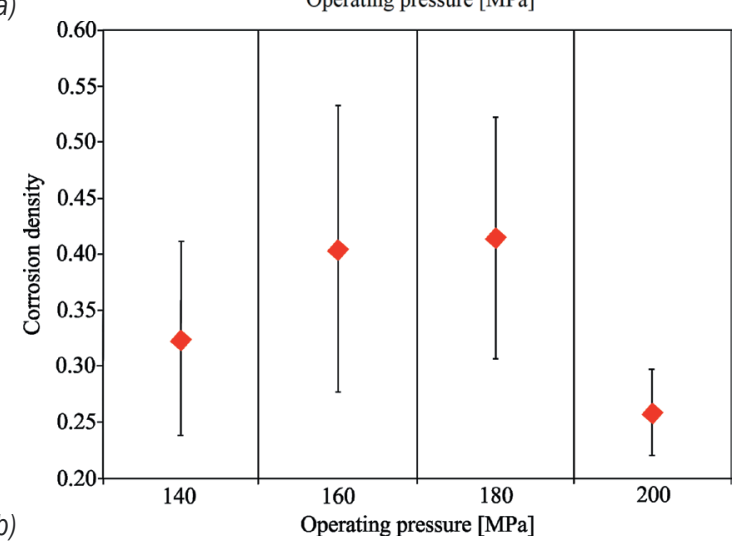

Fig. 7. Summary of results for Bosch fuel injectors working under different operating pressures; a) number of elements affected by corrosion and b) corrosion density
Table 2. Fuel injector repair efficiency in the testing period

\begin{tabular}{ccccc}
\hline \multirow{2}{*}{ Mileage } & \multicolumn{5}{c}{ Number of repaired fuel injectors } \\
\cline { 2 - 5 } & Bosch & Denso & Delphi & Siemens \\
\hline $0-50$ & 8 & 4 & 0 & 0 \\
\hline $51-100$ & 48 & 20 & 24 & 4 \\
\hline $101-150$ & 156 & 28 & 120 & 8 \\
\hline $151-200$ & 488 & 56 & 156 & 24 \\
\hline $201-250$ & 816 & 32 & 60 & 12 \\
\hline $251-300$ & 588 & 16 & 8 & 8 \\
\hline Higher & 24 & 0 & 0 & 0 \\
\hline \multirow{2}{*}{ Summary } & \multicolumn{5}{c}{ Total number of repaired fuel injectors } \\
\cline { 2 - 5 } & 2128 & 156 & 368 & 56 \\
\hline \multirow{2}{*}{ Mileage } & Repair efficiency index at specific mileage [\%] \\
\cline { 2 - 5 } & Bosch & Denso & Delphi & Siemens \\
\hline $0-50$ & 100 & 100 & 100 & 100 \\
\hline $51-100$ & 92 & 100 & 100 & 100 \\
\hline $101-150$ & 93 & 88 & 91 & 100 \\
\hline $151-200$ & 93 & 74 & 89 & 75 \\
\hline $201-250$ & 92 & 53 & 71 & 33 \\
\hline $251-300$ & 88 & 29 & 33 & 22 \\
\hline Higher & 37 & 0 & 0 & 0 \\
\hline \multirow{2}{*}{ Summary } & Repair efficiency index for all manufacturer's designs [\%] \\
\cline { 2 - 5 } & 90 & 61 & 82 & 44 \\
\hline
\end{tabular}

The data presented in Table 2 suggest that repair is no longer effective at high operational mileages. In this respect, Bosch and Delphi fuel injectors, i.e. the designs of manufacturers offering the biggest product line of spare parts, performed most favourably. The fuel injectors being disqualified after main body defects (cracking, shape deformation, thread stripping) or defects in electrical elements (coil winding burnout, damages to piezoelectric crystal stack, breakage of terminal latches) had been found were an exception. The treatment was similar in the case of control solenoid valve corrosion. Attempts to remove corrosion traces using ultrasonic cleaners might result in undesirable softening of plastic housings and defects in insulation. Much lower repair efficiency indicators were obtained for fuel injectors from other manufacturers. In the case of Siemens, which specialises in piezoelectric fuel injectors, the maintenance essentially consisted of external and internal cleaning using only thermo-chemical methods and then to testing on test benches. Given the lack of availability of replacement parts by Siemans, the detection of more serious damages practically eliminated a given fuel injector. The repair of Denso products was possible over a slightly wider range. Some clients decided to use substitute parts that differ with respect to quality from the original elements, although they extend the service life of the fuel injectors. Replacement usually included the precision 
pair (deformation of needle taper, contact zone overheating, external and internal corrosion, guide face scratching or seizure) as well as control valve assembly (seat erosive changes, stem scratching, body surface and valve seating corrosion).

\section{CONCLUSIONS}

The results of the above analysis show that corrosion is a factor significantly affecting the failure frequency of common rail systems. The consequences of its effect are accelerated wear of respective parts and assemblies, while products contaminate the interior of fuel injector and interfere with operating processes. The following conclusions have been drawn from this study:

1. The control valve and armature assemblies, which have direct contact with the fuel being supplied under high pressure, are equally affected by destructive processes of corrosion as nozzles.

2. The wear of electrical elements is least frequent but fuel injector is disqualified from further work (no cleaning or replacement possible).

3. As operational mileages continues to increase, corrosion density increases because corrosion traces are being observed in a larger number of parts, which are then classified as having higher and higher levels of wear.

4. An increase in the injection pressure leads to intensification of corrosive wear, despite design and material modifications in successive fuel injector generations.

5. Availability of spare parts has a fundamental impact on fuel injector repair efficiency because when they are missing (or limited) the elements or assemblies being affected by corrosion at higher levels cannot be replaced.

6. Limitation in the acceptance for repair of fuel injectors from engines with very high mileages results from their poor technical condition, most often precluding the recovery of nominal parameters.

\section{NOMENCLATURE}

CRI common rail injector

CRIN common rail injector (commercial vehicles)

$D_{c} \quad$ corrosion density

$e \quad$ number of elements

FAME fatty acid methyl esters

$L_{i} \quad$ level of corrosion classification for the $i^{\text {th }}$ element

\section{REFERENCES}

[1] Knefel, T. (2012). Technical assessment of Common Rail injectors on the ground of overflow bench tests. Maintenance and Reliability, vol. 14, no. 1, p. 42-53.

[2] Perez, N. (2004). Electrochemistry and Corrosion Science, 1st ed. Kluwer Academic Publishers, Boston, D0I:10.1007/ b118420.

[3] Sharafutdinov, I., Stratiev, D., Shishkova, I., Dinkov, R., Batchvarov, A., Petkov, P., Rudnev, N. (2012). Cold flow properties and oxidation stability of blends of near zero sulfur diesel from Ural crude oil and FAME from different origin. Fuel, vol. 96, p. 556-567, D0l:10.1016/j.fuel.2011.12.062.

[4] Shiwei, L., Lu, L., Shitao, Y., Congxia, X., Fusheng, L., Zhanqian, S. (2010). Polymerization of Fatty Acid Methyl Ester Using Acidic Ionic Liquid as Catalyst. Chinese Journal of Catalysis, vol. 31, no. 11-12, p. 1433-1438, D0l:10.1016/S18722067(10)60128-3.

[5] Galle, J., Verhelst, S., Sierens, R., Goyos, L., Castaneda, R., Verhaege, M., Vervaeke, L., Bastiaen, M. (2012). Failure of fuel injectors in a medium speed diesel engine operating on biooil. Biomass and Bioenergy, vol. 40, p. 27-35, D0l:10.1016/j. biombioe.2012.01.041.

[6] Schleicher, T., Werkmeister, R., Russ, W., Meyer-Pittroff, R. (2009). Microbiological stability of biodiesel - diesel mixtures. Bioresource Technology, vol. 100, no. 2, p. 724-730, Dol:10.1016/j.biortech.2008.07.029.

[7] Aquino, I.P., Hernandez, R.P.B., Chicoma, D.L., Pinto, H.P.F., Aoki, I.V. (2012). Influence of light, temperature and metallic ions on biodiesel degradation and corrosiveness to copper and brass. Fuel, vol. 102, p. 795-807, D0l:10.1016/j. fuel.2012.06.011.

[8] Norouzi, S., Eslami, F., Wyszynski, M.L., Tsolakis, A. (2012). Corrosion effect of RME in blends with ULSD on aluminium and copper. Fuel Processing Technology, vol. 104, p. 204-210, D0I:10.1016/J.fuproc.2012.05.016.

[9] Chauhan, B.S., Kumar, N., Pal, S.S., Jun, Y.D. (2011). Experimental studies on fumigation of ethanol in a small capacity diesel engine. Energy, vol. 36, no, 2, p. 1030-1038, DOl:10.1016/j.energy.2010.12.005.

[10] Hansen, A.C., Zhang, Q., Lyne, P.W.L. (2005). Ethanol - diesel fuel blends - a review. Bioresource Technology, vol. 96, no. 2, p. 277-285, D0l:10.1016/j.biortech.2004.04.007.

[11] Kowalski, K. (2006). Utilization of military vehicles under shortage of basic fuels. Maintenance and Reliability, vol. 4, p. $16-21$.

[12] Jósko, M., Kołodziejski, M. (2008). Selected exploitation problems of agricultural vehicles in the scope of their servicing. Journal of Research and Applications in Agricultural Engineering, vol. 53, no. 2, p. 5-7.

[13] Taflan, R.A., Karamangil, M.I. (2012). Statistical corrosion evaluation of nozzles used in diesel CRI systems. Fuel, vol. 102, p. 41-48, D0l:10.1016/j.fuel.2012.06.037.

[14] Günther, H. (2012). Common - Rail - Systeme in der Werkstattpraxis. Technik, Prüfung, Diagnose, $4^{\text {th }}$ ed., Krafthand Verlag Walter Schultz GmbH, Bad Wörihofen.

[15] Postrioti, L., Malaguti, S., Bosi, M., Buitoni, G., Piccinini, S., Bagli, G. (2014). Experimental and numerical characterization 
of a direct solenoid actuation injector for Diesel engine applications. Fuel, vol. 118, p. 316-328, D0l:10.1016/J. fuel.2013.11.001.

[16] Boudy, F., Seers, P. (2009). Impact of physical properties of biodiesel on the injection process in a common-rail direct injection system. Energy Conversion and Management, vol. 50, no. 12, p. 2905-2912, D0l:10.1016/J.enconman.2009.07.005.

[17] Olszowski, S. (2010). Examination of permeating oil causes in new generation diesel engines. Transcomp - XIV international conference, Computer systems aide science, industry and transport, vol. 6, p. 2581-2588.

[18] Payri, F., Bermu'dez, V., Payri, R., Salvador, F.J. (2004). The influence of cavitation on the internal flow and the spray characteristics in diesel injection nozzles. Fuel, vol. 83, no. 4-5, p. 419-431, D0l:10.1016/j.fuel.2003.09.010.

[19] Idzior, M. (2006). Tendencies of the construction changes in self-ignition engines injectors. Motrol - Motorization and Power Industry in Agriculture, vol. 8, p. 81-91. 